\title{
Point-of-care Ultrasound for Anesthetic Management of a Severely Obese Parturient
}

\author{
${ }^{1}$ Harsha Narkhede, ${ }^{2}$ Nisha Gowani, ${ }^{3}$ Shrikanta Oak, ${ }^{4}$ Indrani H Chincholi
}

\begin{abstract}
There is a rising trend in obesity in the general population, thus it is not uncommon to have an obese obstetric parturient. The anesthesiologist should be well equipped to provide regional anesthesia. Ultrasonography is a useful tool to guide anesthesiologists in providing a successful regional block in obese parturient. We have successfully performed regional block in a severely obese parturient with use of point-of-care ultrasound (POCUS).
\end{abstract}

Keywords: Obese, Obstetric, Point-of-care ultrasound, Spinal anesthesia.

How to cite this article: Narkhede H, Gowani N, Oak S, Chincholi IH. Point-of-care Ultrasound for Anesthetic Management of a Severely Obese Parturient. Res Inno in Anesth 2018;3(1):29-31.

\section{Source of support: Nil}

Conflict of interest: None

\section{INTRODUCTION}

Point-of-care ultrasound is the use of a portable ultrasound at patient's bedside for essential diagnostic and therapeutic purposes. ${ }^{1}$ The use of ultrasound by clinicians has excelled medical practice and safety of patients. A rising trend in use of ultrasound in anesthetic management has been noted. Recent studies reveal an increase in the prevalence of obesity in Indian women from 10.6 to $12.6 \% .^{2}$ Providing neuraxial anesthesia to an obese parturient undergoing cesarean section is a clinically challenging procedure, thus leading to the advent of POCUS, facilitating anesthesia. ${ }^{1,3-5}$ The POCUS can additionally be used as a guide to administering a transversus abdominis plane (TAP) block for postoperative analgesia, thus reducing the requirement for opioid analgesics.

We report successful anesthetic and postoperative analgesic management with use of ultrasound to locate

\footnotetext{
${ }^{1}$ Assistant Professor, ${ }^{2}$ Senior Resident, ${ }^{3}$ Associate Professor ${ }^{4} \mathrm{Head}$

${ }^{1-4}$ Department of Anesthesiology, King Edward Memorial Hospital and Seth Gordhandas Sunderdas Medical College Mumbai, Maharashtra, India

Corresponding Author: Shrikanta Oak, Associate Professor Department of Anesthesiology, King Edward Memorial Hospital and Seth Gordhandas Sunderdas Medical College, Mumbai Maharashtra, India, e-mail: shrikanta_oak@yahoo.com
}

the subarachnoid space and TAP in a severely obese parturient undergoing elective cesarean section.

\section{CASE REPORT}

A 30-year-old obese female with gravidarum 2, parity 1 , living 1; with a prepregnancy weight of $94 \mathrm{~kg}$, height of $158 \mathrm{~cm}$, body mass index (BMI) of $37.6 \mathrm{~kg} / \mathrm{m}^{2}$, and a weight of $107 \mathrm{~kg}$ at full term, was posted for elective cesarean section in view of previous cesarean section (Fig. 1). She gave a history suggestive of obstructive sleep apnea, and no other major clinical findings were present. Written informed consent was obtained and adequate starvation confirmed. All standard monitors were attached and a 20-gauge intravenous cannula was secured. Standard antiaspiration and antimicrobial prophylaxis was given. Preloading with crystalloid Ringer's lactate was done. Emergency drug tray including 20\% intralipid with difficult airway cart was kept ready.

Preprocedure ultrasound scan of lumbar spine was done in sitting position with curvilinear probe. Probe was placed over the sacrum and the hyperechoic line was visualized. The transducer was then directed cranially. The first intervertebral space located was L5-S1. The probe was directed further cranially and intervertebral spaces were counted upward; thus L4 to L5 and L3 to L4 spaces were located. The probe was then turned $90^{\circ}$ to obtain transverse view and was adjusted at the level of L3 to L4 till anterior chamber was visible. Horizontal skin and vertical skin marking was made along the long and short axis of the probe respectively where anterior chamber was best seen. The depth of subarachnoid space measured with caliper was $6.6 \mathrm{~cm}$. Subarachnoid block was given successfully in a single midline attempt through the intersection of the two lines. Drug $1.5 \mathrm{cc}$ of $0.5 \%$ heavy bupivacaine and $25 \mu \mathrm{g}$ fentanyl was given with 23-gauge 3.5-inch Quincke spinal needle after free flow of clear cerebrospinal fluid. The angle of insertion of spinal needle was the same as the angulation of the probe. The sensory block up to dermatome T4 and motor block grade IV on Bromage scale was achieved. Intraoperative hemodynamics were stable. Duration of surgery was 90 minutes. After the last skin suture, the patient was given a real-time ultrasound-guided bilateral TAP block with $20 \mathrm{~mL}$ of $0.25 \%$ injection bupivacaine. Duration of postoperative analgesia with TAP block lasted 12 hours. 


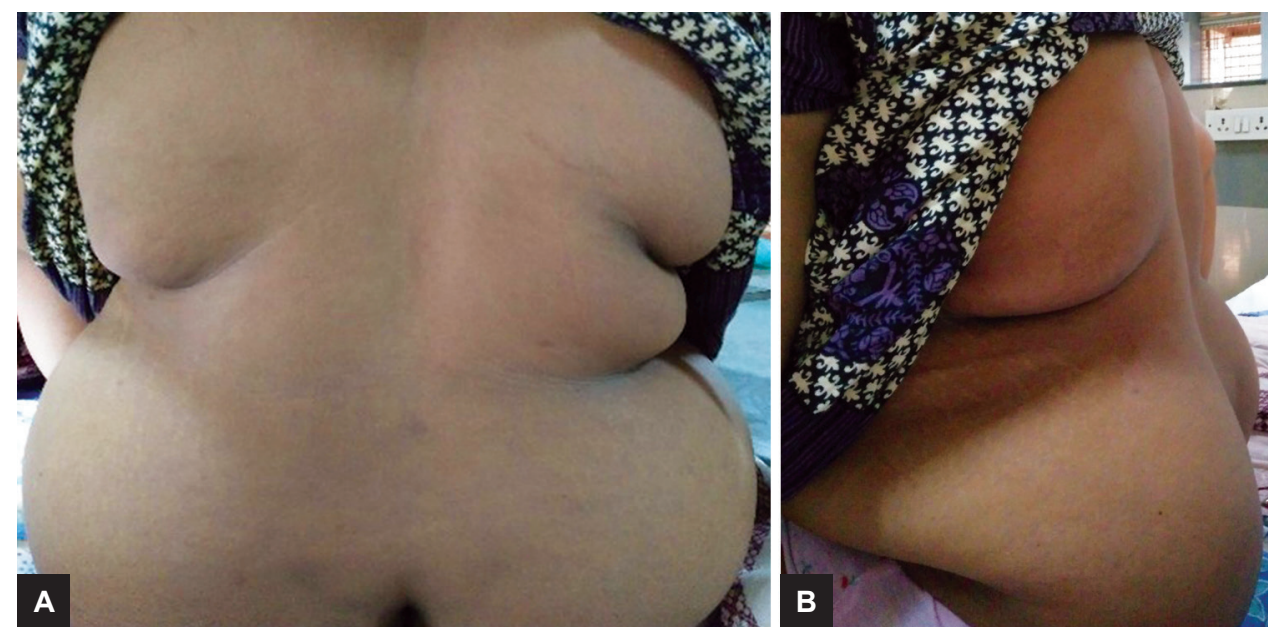

Figs 1A and B: Preanesthetic examination of anticipated difficult anatomical landmarks

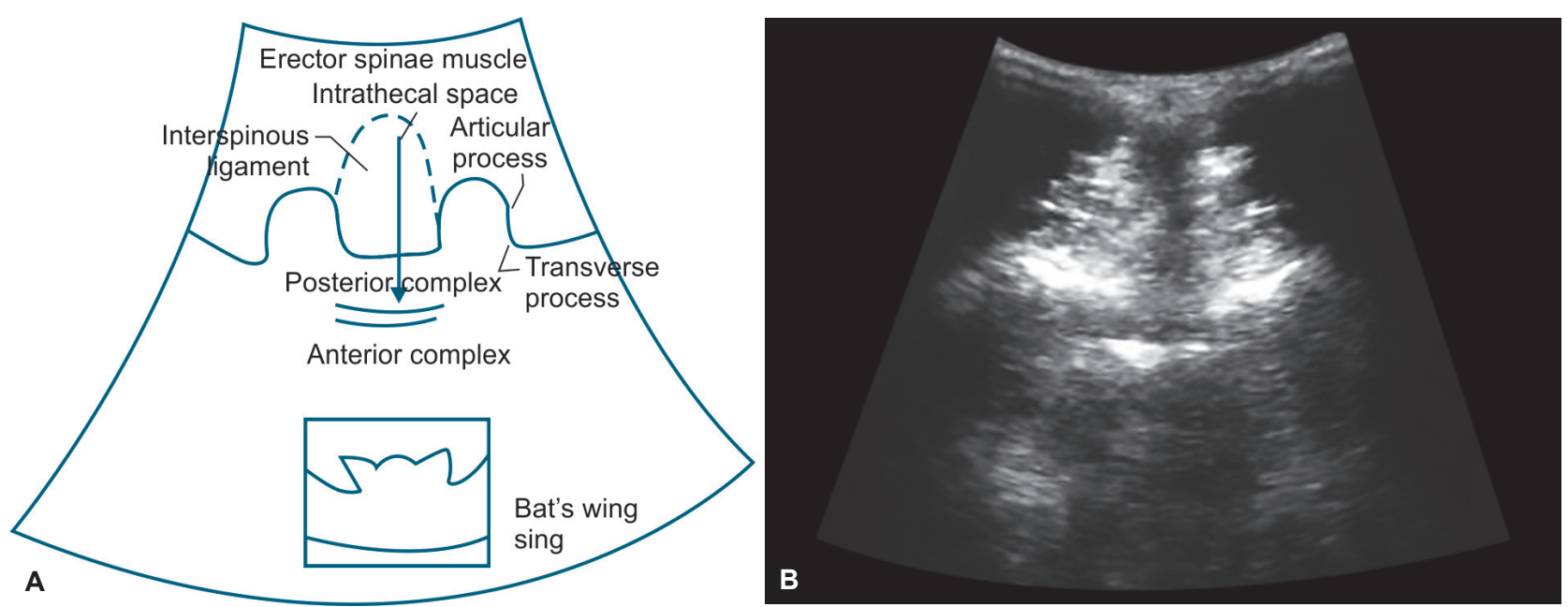

Figs 2A and B: The ultrasonographic picture and schematic diagram

\section{DISCUSSION}

Obese women undergoing cesarean sections are at increased risk for failed tracheal intubation, postoperative hypoxemia, atelectasis, deep vein thrombosis (DVT), and pulmonary embolism. ${ }^{6}$ According to the Royal College of Obstetricians and Gynaecologists, our patient had a BMI of $37.6 \mathrm{~kg} / \mathrm{m}^{2}$ and belongs to class 2 obesity. Regional anesthesia wherever possible is the best choice in the management of these patients, as it avoids airway manipulation, reduced postoperative hypoxemia, nausea, and vomiting; provides excellent postoperative pain relief, and thus helps to reduce opioid consumption, allowing early mobilization, and decreases the risk for embolism.

Obese patients have reduced ability to flex and the anesthesiologist faces difficulty in locating the intervertebral spaces via palpation due to increased subcutaneous fat. ${ }^{5,7,8}$ Thus, the patient may have to sustain multiple needle pricks which may lead to patient discomfort, increased chances of spinal hematoma, neural injury, and postdural puncture headache. On preoperative examination, we anticipated a difficult spinal anesthesia; therefore, we performed the procedure with ultrasound guidance. Lebbi et $\mathrm{al}^{9}$ had multiple unsuccessful attempts in locating subarachnoid space by anatomical landmark technique in a patient with BMI of $53 \mathrm{~kg} / \mathrm{m}^{2}$; the procedure was then abandoned and ultrasoundguided spinal anesthesia was given in a single successful attempt. This can be overcome by POCUS, facilitating the point of needle insertion and angulation, estimating the depth of subarachnoid space. Significant evidence exists that supports the role of ultrasound in improving precision and efficacy of neuraxial anesthetic technique. ${ }^{10}$ The spinal needle should be advanced only after clear visualization of the anterior chamber at the intervertebral space. We acquired a distance of $6.6 \mathrm{~cm}$ in our obese parturient patient with a BMI of $37.6 \mathrm{~kg} /$ $\mathrm{m}^{2}$ (Fig. 2), whereas Yasuhiro morimoto et al in their case report acquired the distance from skin to posterior dura of $8.9 \mathrm{~cm}$ in a nonparturient obese patient with a BMI of $50 \mathrm{~kg} / \mathrm{m}^{2,11}$ 
We have successfully located the subarachnoid space in a single midline attempt by a preprocedure ultrasound scan of lumbar spine.

In a study by Chin et al, ${ }^{12}$ ultrasound-guided spinal anesthesia was successful in single midline attempts in $84 \%$ patients with difficult anatomical landmarks in general population.

Requirement for adequate postoperative analgesia should not be neglected, as it facilitates early mobilization and reduces risk of DVT and embolism.

Thus, a TAP block was provided to the patient postoperative as a part of multimodal analgesia, reducing opioid consumption, delayed time for recue analgesic, and decreased visual analog scale at movement and rest. The successful localization of the TAP in our obese patient was done via ultrasound guidance in accordance with the concept of POCUS, and the patient was comfortable and did not require any additional analgesic for 18 hours postoperative. Similarly, a randomized trial performed by Mankikar et $\mathrm{al}^{13}$ showed a reduced requirement for analgesics for 24 hours postoperative, in parturients who underwent cesarean section.

The ultrasound machine has limitations too. A lowfrequency curvilinear probe is required to scan deeper structures, thus giving low-resolution images. Hand-eye coordination is a challenging task while performing realtime procedures, thus requiring a learning curve. Due to the osseous spinous structure, scanning is possible through a narrow acoustic window. The images obtained in an obese patient are less distinct due to attenuation of the sound waves as they travel through the fatty tissue. A phase aberration effect occurs by varying speed of sound in irregularly shaped adipose tissue. ${ }^{14}$

\section{CONCLUSION}

The POCUS is a useful tool for the anesthesiologist in providing successful regional block to severely obese parturient patients with difficult surface anatomical landmarks.

\section{REFERENCES}

1. Moore CL, Copel JA. Point-of-care ultrasonography. N Engl J Med 2011 Feb;364(8):749-757.

2. Garg C, Khan SA, Ansari SH, Garg M. Prevalence of obesity in Indian women. Obes Rev 2010 Feb;11(2):105-108.

3. Vallejo MC. Anesthetic management of the morbidly obese parturient. Curr Opin Anaesthesiol 2007 Jun;20(3):175-180.

4. Sprung J, Bourke DL, Grass J, Hammel J, Mascha E, Thomas P, Tubin I. Predicting the difficult neuraxial block: a prospective study. Anesth Analg 1999 Aug;89(2):384-389.

5. de Filho GR, Gomes HP, da Fonseca MH, Hoffman JC, Pederneiras SG, Garcia JH. Predictors of successful neuraxial block: a prospective study. Eur J Anaesthesiol 2002 Jun;19(6):447-451.

6. Rao DP, Rao VA. Morbidly obese parturient: challenges for the anaesthesiologist, including managing the difficult airway in obstetrics. What is new? Indian J Anaesth 2010 Nov;54(6):508-521.

7. Ellinas EH, Eastwood DC, Patel SN, Maitra-D'Cruze AM, Ebert TJ. The effect of obesity on neuraxial technique difficulty in pregnant patients: a prospective, observational study. Anesth Analg 2009 Oct;109(4):1225-1231.

8. O'Donnell D, Prasad A, Perlas A. Ultrasound-assisted spinal anesthesia in obese patients. Can J Anesth Can Anesth 2009 Dec;56(12):982-983.

9. Lebbi MA, Trabelsi W, Bousselmi R, Messaoudi A, Labbène I, Ferjani M. Ultrasound-guided spinal anesthesia in an obese patient. Tunis Med 2014 Feb;92(2):164-166.

10. Perlas A, Chaparro LE, Chin KJ. Lumbar neuraxial ultrasound for spinal and epidural anesthesia: a systematic review and meta-analysis. Reg Anesth Pain Med 2016 Mar-Apr; 41(2):251-260.

11. Morimoto $Y$, Ihara $Y$, Shimamoto $Y$, Shiramoto H. Use of ultrasound for spinal anesthesia in a super morbidly obese patient. J Clin Anesth 2017 Feb;36:88-89.

12. Chin KJ, Perlas A, Chan V, Brown-Shreves D, Koshkin A, Vaishnav V. Ultrasound imaging facilitates spinal anesthesia in adults with difficult surface anatomic landmarks. Anesthesiology 2011 Jul;115(1):94-101.

13. Mankikar MG, Sardesai SP, Ghodki PS. Ultrasound-guided transversus abdominis plane block for post-operative analgesia in patients undergoing caesarean section. Indian J Anaesth 2016 Apr;60(4):253-257.

14. Saranteas T. Limitations in ultrasound imaging techniques in anesthesia: obesity and muscle atrophy? Anesth Analg 2009 Sep;109(3):993-994. 